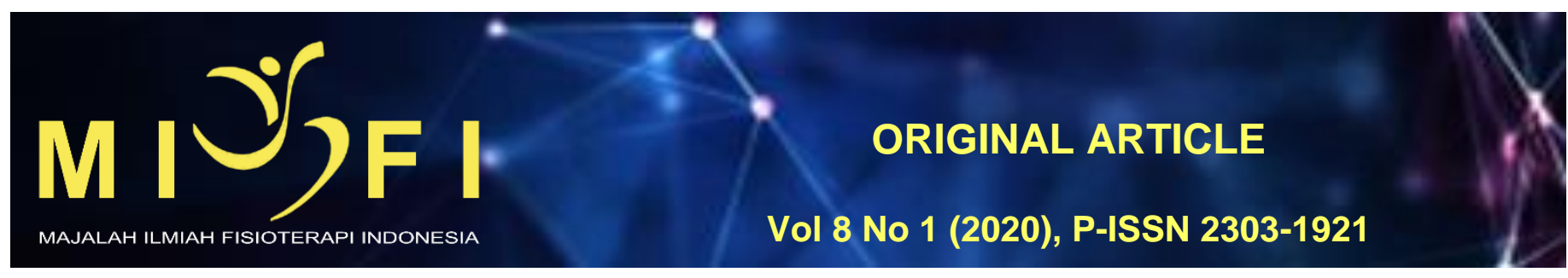

\title{
PREVALENSI KEJADIAN CHRONIC ANKLE INSTABILITY PADA ATLET BASKET SMA DI KABUPATEN BADUNG
}

\author{
Vimala Krishna Prasada ${ }^{1}$, Ni Wayan Tianing ${ }^{2}$, Putu Ayu Sita Saraswati ${ }^{3}$, I Wayan Gede Sutadarma ${ }^{4}$ \\ ${ }^{1}$ Program Studi Sarjana Fisioterapi dan Profesi Fisioterapi, Fakultas Kedokteran Universitas Udayana \\ ${ }^{2,4}$ Departemen Biokimia, Fakultas Kedokteran Universitas Udayana \\ ${ }^{3}$ Departemen Fisioterapi, Fakultas Kedokteran Universitas Udayana \\ vimalaprasada@gmail.com
}

\begin{abstract}
ABSTRAK
Cedera pergelangan kaki (ankle) merupakan cedera yang paling sering dialami oleh atlet basket, dan sprain pada ligamen bagian lateral merupakan diagnosis yang paling umum. Hal tersebut dapat menyebabkan seorang atlet mengalami chronic ankle instability (CAI). Kondisi ini ditandai dengan adanya cedera berulang dan perasaan goyang pada pergelangan kaki. Tujuan dari penelitian ini adalah untuk mengetahui prevalensi kejadian chronic ankle instability pada atlet basket SMA di Kabupaten Badung. Penelitian ini merupakan penelitian deskriptif cross-sectional yang dilakukan pada bulan Maret hingga Mei 2019. Pengambilan sampel menggunakan teknik purposive sampling dengan jumlah sampel sebanyak 162 orang. Kuisioner Cumberland Ankle Instability Tool digunakan untuk menentukan responden yang mengalami CAI. Faktor lain seperti jenis kelamin, indeks massa tubuh (IMT), riwayat cedera sprain ankle, dan ada atau tidaknya perawatan medis pasca cedera sprain ankle juga dicatat pada penelitian ini. Hasil penelitian menunjukan prevalensi kejadian chronic ankle instability sebanyak $51,2 \%$. Responden dengan jenis kelamin laki-laki, IMT overweight, memiliki riwayat sprain ankle dan memperoleh penanganan medis pasca mengalami cedera sprain ankle memiliki kecenderungan yang lebih besar untuk mengalami CAl.
\end{abstract}

Kata Kunci: chronic ankle instability, atlet basket SMA

\section{PREVALENCE OF CHRONIC ANKLE INSTABILITY IN HIGH SCHOOL BASKETBALL ATHLETE AT BADUNG REGENCY}

\begin{abstract}
Ankle injury is the most common injury experienced by basketball athletes, and the sprain in the lateral ligament is the most common diagnosis. This can cause an athlete to experience chronic ankle instability (CAI). This condition is characterized by repeated injuries and a sensation of giving way of the ankle. The purpose of this study was to determine the prevalence of chronic ankle instability in high school basketball athletes in Badung Regency. This research is a cross-sectional descriptive study conducted from March to May 2019. Sampling used purposive sampling technique with a total sample of 162 people. The Cumberland Ankle Instability Tool questionnaire was used to determine respondents who experienced CAl. Other factors such as gender, body mass index (BMI), history of ankle sprain injury, and the presence or absence of medical treatment after an ankle sprain injury were also noted in this study. The results showed a prevalence of chronic ankle instability of $51.2 \%$. Respondents with male sex, overweight BMI, having a history of ankle sprain and obtaining medical treatment after an ankle sprain injury had a greater tendency to experience CAI.

Keywords: chronic ankle instability, high school basketball athlete
\end{abstract}




\section{PENDAHULUAN}

Permainan basket merupakan salah satu jenis olahraga yang sangat populer di masyarakat. Kepopuleran olahraga ini dapat terlihat jelas, hampir setiap sekolah memiliki ekstrakurikuler basket yang dapat diikuti bagi siswa yang memiliki minat dengan olahraga ini. Kompetisi basket antar sekolah banyak diadakan dan menjadi kegiatan rutin setiap tahunnya. Banyaknya kompetisi yang diadakan tentu menjadi motivasi bagi setiap sekolah untuk terus berlatih dan berlomba-lomba menjadi yang terbaik. Sehingga menjaga kondisi fisik setiap atlet juga sangat penting.

Setiap olahraga termasuk basket penuh dengan risiko yang bisa menyebabkan cedera. Cedera pada pergelangan kaki (ankle) merupakan cedera yang paling sering dialami oleh atlet basket. Sebanyak $35,9 \%$ atlet basket SMA perempuan dan $43,2 \%$ atlet basket SMA laki-laki di Amerika Serikat mengalami cedera ankle dengan diagnosis yang paling umum adalah sprain pada ligamen bagian lateral. ${ }^{1}$ Di Indonesia, cedera sprain ankle merupakan kasus yang paling sering terjadi pada atlet yang mengikuti pelatda PON DKI Jakarta tahun 2012 yakni sebanyak 41,1\%. ${ }^{2}$ Cedera ini dapat menyebabkan atlet mengalami gangguan dan gejala sisa yang umum dirasakan seperti nyeri, ketidakstabilan, krepitasi dan kelemahan. Seorang atlet yang memiliki riwayat sprain ankle berisiko untuk mengalami cedera kembali pada pergelangan kakinya. Mobilisasi yang terlalu cepat dan rehabilitasi yang kurang baik dapat menimbulkan gejala sisa dan berujung menjadi Chronic Ankle Instability (CAl). ${ }^{3}$

Chronic ankle instability adalah istilah untuk mendefinisikan suatu kondisi inadekuat pada pergelangan kaki akibat riwayat cedera sebelumnya. Mechanical Instability (ketidakstabilan mekanik), functional instability (ketidakstabilan fungsional), dan recurrent sprain (sprain berulang) pada ankle merupakan bagian yang ada pada CAI. Functional instability ditandai dengan adanya perasaan tidak stabil atau goyang pada sendi pergelangan kaki. Sedangkan mechanical instability mengacu pada kelemahan struktur, dalam hal ini adalah kelemahan ligamen-ligamen yang menyangga sendi pergelangan kaki. Ketiga bagian tersebut dapat muncul secara gabungan ataupun independen. ${ }^{4}$

Kesadaran masyarakat khususnya para atlet masih kurang terhadap penanganan cedera. Akibatnya kemungkinan seorang atlet untuk mengalami kondisi CAI setelah mengalami sprain ankle tentu cukup tinggi. Penelitian sebelumnya menunjukan frekuensi kejadian CAl lebih tinggi pada atlet yang tidak mencari perawatan medis setelah sprain ankle dibandingkan dengan atlet yang mendapatkan perawatan dan $40,5 \%$ atlet SMA dengan riwayat sprain ankle mengalami CAI dikemudian hari. ${ }^{5}$ Apabila dibiarkan kondisi ini dapat mengganggu performa seorang atlet dan tidak menutup kemungkinan dapat memicu terjadinya cedera berulang. ${ }^{6}$

Sudah banyak studi prevalensi yang menunjukan frekuensi dan tingkat keparahan cedera sprain ankle, tetapi masih sedikit yang melakukan studi prevalensi kejadian chronic ankle instability. Di Indonesia, khususnya di Bali, screening awal dan pencatatan status kesehatan bagi atlet basket SMA sangat jarang dilakukan sehingga informasi kondisi fisik dari masing-masing atlet masih kurang diketahui. Jika identifikasi kondisi CAI sudah dilakukan maka pencegahan dan penanganan untuk kondisi ini dapat dirancang dengan baik. ${ }^{5}$

Dapat dikatakan bahwa sangat penting untuk dapat mengidentifikasi kondisi CAI pada atlet basket SMA. Berdasarkan uraian di atas penulis melakukan penelitian untuk mengetahui prevalensi dari kejadian chronic ankle instability pada atlet basket SMA di Kabupaten Badung.

\section{METODE}

Rancangan penelitian ini menggunakan rancangan deksriptif cross-sectional. Beberapa SMA di Kabupaten Badung dipilih menjadi lokasi penelitian. Penelitian dilaksanakan pada bulan Maret sampai Mei 2019. Jumlah sampel pada penelitian ini yaitu 162 orang. Sampel dipilih menggunakan teknik purposive sampling dan memenuhi kriteria inklusi dan eksklusi diantaranya merupakan anggota dari tim basket di sekolahnya dan tidak memiliki riwayat patah tulang atau pernah menjalani operasi pada pergelangan kaki.

CAI ditentukan menggunakan kuisioner Cumberland Ankle Instability Tool (CAIT). Responden diklasifikasikan mengalami CAI apabila memperoleh skor <24 pada kuisioner CAIT. Beberapa faktor yang mempengaruhi terjadinya CAI juga diteliti pada penelitian ini, diantaranya jenis kelamin, indeks massa tubuh (IMT), riwayat cedera sprain ankle, dan ada atau tidaknya perawatan medis pasca cedera sprain ankle.

Penelitian diawali dengan memberikan penjelasan mengenai tujuan dan manfaat dari penelitian ini. Kemudian dilakukan pengukuran tinggi badan dan berat badan. Selanjutnya dilakukan anamnesis untuk memperloleh informasi tentang riwayat cedera dan riwayat operasi dari responden. Apabila mereka pernah menjalani operasi di sekitar pergelangan kaki, maka akan dieksklusi dari penelitian ini.

Data yang telah dikumpulkan kemudian dianalisis secara deskriptif menggunakan aplikasi SPSS v. 20. Melalui data tersebut akan dilihat prevalensi dari CAI dan distribusinya berdasarkan faktor-faktor yang mempengaruhi.

\section{HASIL}

Karakteristik responden berdasarkan jenis kelamin, IMT, dan riwayat cedera sprain ankle adalah sebagai berikut.

Tabel 1. Karakteristik Responden

\begin{tabular}{|c|c|c|c|}
\hline & eristik & $\begin{array}{c}\text { Frekuensi } \\
\text { (n) }\end{array}$ & $\begin{array}{c}\text { Persentase } \\
(\%)\end{array}$ \\
\hline \multicolumn{4}{|c|}{ Jenis Kelamin } \\
\hline & Laki-laki & 88 & 54,3 \\
\hline & Perempuan & 74 & 45,7 \\
\hline IMT & $\begin{array}{l}\text { Normal } \\
\text { Overweight }\end{array}$ & $\begin{array}{c}120 \\
28\end{array}$ & $\begin{array}{l}74,1 \\
17,3\end{array}$ \\
\hline
\end{tabular}




\begin{tabular}{ccc}
\hline Obesitas & 14 & 8,6 \\
Riwayat Sprain Ankle & & \\
Pernah & 86 & 53,1 \\
Tidak & 76 & 46,9 \\
\hline
\end{tabular}

Berdasarkan tabel 1 diperoleh informasi bahwa frekuensi responden laki-laki sebanyak 88 orang (54,3\%), sedangkan responden perempuan frekuensinya sebanyak 74 orang $(45,7 \%)$. Karakteristik sampel berdasarkan IMT didapatkan sebanyak 120 orang $(74,1 \%)$ memiliki IMT dengan kategori normal, 28 orang (17,3\%) ketegori overweight, dan 14 orang $(8,6 \%)$ kategori obesitas. Kemudian jumlah responden yang pernah mengalami sprain ankle sebanyak 86 orang $(53,1 \%)$, sedangkan sebanyak 76 orang $(46,9 \%)$ tidak pernah mengalaminya.

Tabel 2. Distribusi Penanganan Medis Pasca Cedera Sprain Ankle

\begin{tabular}{ccc}
\hline $\begin{array}{c}\text { Penanganan Medis } \\
\text { Pasca Sprain Ankle }\end{array}$ & $\begin{array}{c}\text { Frekuensi } \\
(\mathbf{n})\end{array}$ & $\begin{array}{c}\text { Persentase } \\
(\%)\end{array}$ \\
\hline Ya & 18 & 20,9 \\
Tidak & 68 & 79,1 \\
\hline
\end{tabular}

Seperti yang tertera pada tabel 2 terdapat informasi mengenai frekuensi responden yang memperoleh penanganan medis pasca cedera sprain ankle. Dari tabel tersebut diketahui bahwa dari 86 orang yang memiliki riwayat cedera sprain ankle, sebanyak 68 orang $(79,1 \%)$ tidak mencari ataupun mendapatkan pelayanan medis. Hanya 18 orang $(20,9 \%)$ yang mendapatkan pelayanan medis setelah mereka cedera.

Tabel 3. Prevalensi CAI

\begin{tabular}{llcc}
\hline & & $\begin{array}{c}\text { Frekuensi } \\
\text { (n) }\end{array}$ & $\begin{array}{c}\text { Persentase } \\
\text { (\%) }\end{array}$ \\
\hline Prevalensi CAI & & & \\
& Ya & 83 & 51,2 \\
Jenis CAI & Tidak & 79 & 48,8 \\
& & & \\
& Bilateral & 45 & 54,2 \\
& Unilateral & 38 & 45,8 \\
\hline
\end{tabular}

Berdasarkan tabel 3 diketahui bahwa dari 162 orang responden, 83 orang $(51,2 \%)$ diantaranya mengalami CAI dan 79 orang $(48,8 \%)$ lainnya tidak mengalami kondisi tersebut. Kemudian dari 83 orang yang mengalami CAl, dibagi lagi menjadi 2 jenis yaitu CAI bilateral dan unilateral. Hasilnya sebanyak 45 orang $(54,2 \%)$ mengalami CAI bilateral, sedangkan CAI unilateral dialami oleh 38 responden $(45,8 \%)$.

Tabel 4. Distribusi CAI Berdasarkan Faktor yang Mempengaruhi

\begin{tabular}{|c|c|c|c|c|c|}
\hline \multirow{2}{*}{ CAI } & \multirow{2}{*}{ Jenis Kelamin } & \multirow{2}{*}{ IMT } & \multicolumn{2}{|c|}{ Riwayat Sprain Ankle } & \multirow{2}{*}{ Total } \\
\hline & & & Pernah & Tidak & \\
\hline \multirow{8}{*}{ Ya } & \multirow{4}{*}{ Laki-laki } & Normal & 28 & 8 & 36 \\
\hline & & Overweight & 8 & 0 & 8 \\
\hline & & Obesitas & 2 & 2 & 4 \\
\hline & & Total & 38 & 10 & 48 \\
\hline & \multirow{4}{*}{ Perempuan } & Normal & 15 & 9 & 24 \\
\hline & & Overweight & 4 & 4 & 8 \\
\hline & & Obesitas & 3 & 0 & 3 \\
\hline & & Total & 22 & 13 & 35 \\
\hline \multirow{8}{*}{ Tidak } & \multirow{4}{*}{ Laki-laki } & Normal & 12 & 13 & 25 \\
\hline & & Overweight & 4 & 6 & 10 \\
\hline & & Obesitas & 2 & 3 & 5 \\
\hline & & Total & 18 & 22 & 40 \\
\hline & \multirow{4}{*}{ Perempuan } & Normal & 6 & 29 & 35 \\
\hline & & Overweight & 0 & 2 & 2 \\
\hline & & Obesitas & 2 & 0 & 2 \\
\hline & & Total & 8 & 31 & 39 \\
\hline
\end{tabular}

Seperti yang tertera pada tabel 4 diketahui bahwa dari 88 orang responden yang berjenis kelamin laki-laki, sebanyak 48 orang $(54,5 \%)$ mengalami CAI. Kemudian pada sampel berjenis kelamin perempuan, dari 74 orang terdapat 35 orang $(47,3 \%)$ yang mengalami CAI.

Berdasarkan faktor IMT diperoleh informasi bahwa pada kategori IMT normal sebanyak 60 orang responden (50\%) mengalami CAI. Hal tersebut juga terjadi pada kategori obesitas, dimana sebanyak 7 orang responden (50\%) mengalami CAI. Sedangkan pada kategori overweight, sebanyak 16 orang $(57,1 \%)$ mengalami CAl.

Berdasarkan faktor riwayat sprain ankle dapat diketahui bahwa dari 86 orang yang sebelumnya pernah mengalami cedera sprain ankle, sebanyak 60 orang $(69,8 \%)$ mengalami CAl. Kemudian dari 76 orang yang tidak memiliki riwayat cedera sprain ankle, terdapat 23 orang (30,3\%) yang mengalami CAI.

Tabel 5. Distribusi CAI dari Responden yang Memperoleh

dan Tidak Memperoleh Penanganan Medis Pasca Cedera Sprain Ankle

CAI IMT Penanganan Medis Pasca Sprain Ankle Total




\begin{tabular}{|c|c|c|c|c|}
\hline & & Tidak & Ya & \\
\hline \multirow{4}{*}{ Ya } & Normal & 35 & 8 & 43 \\
\hline & Gemuk & 8 & 4 & 12 \\
\hline & Obesitas & 4 & 1 & 5 \\
\hline & Total & 47 & 13 & 60 \\
\hline \multirow{4}{*}{ Tidak } & Normal & 15 & 3 & 18 \\
\hline & Gemuk & 3 & 1 & 4 \\
\hline & Obesitas & 3 & 1 & 4 \\
\hline & Total & 21 & 5 & 26 \\
\hline
\end{tabular}

Berdasarkan tabel 5.5 diperoleh informasi sebanyak 47 orang $(69,1 \%)$ yang tidak memperoleh penanganan medis mengalami CAI. Pada responden yang memperoleh penanganan medis, sebanyak 13 orang $(72,2 \%)$ mengalami CAI.

\section{DISKUSI}

Hasil penelitian pada 162 responden menunjukan jumlah responden laki-laki (54,3\%) lebih banyak dibandingkan responden perempuan (45,7\%). Berdasarkan IMT, jumlah responden yang memiliki IMT dengan kategori normal merupakan yang terbanyak $(74,1 \%)$, kemudian diikuti oleh IMT kategori overweight $(17,3 \%)$, dan yang paling sedikit jumlahnya adalah IMT kategori obesitas $(8,6 \%)$. Selanjutnya berdasarkan riwayat cedera sprain ankle, terdapat lebih banyak responden yang pernah mengalami sprain ankle sebelumnya $(53,1 \%)$ dibandingkan yang tidak pernah mengalaminya (46,9\%). Pada responden yang pernah mengalami sprain ankle lebih banyak yang tidak mencari ataupun memperoleh penanganan medis setelah mereka cedera $(79,1 \%)$ dibandingkan yang memperoleh penanganan medis $(20.9 \%)$.

Distribusi penanganan medis yang diperoleh pasca cedera sprain ankle pada penelitian ini sesuai dengan penelitian sebelumnya dimana lebih dari setengah atlet basket yang menjadi responden dalam penelitian tersebut $(56,8 \%)$ tidak memperoleh ataupun mencari penanganan medis profesional. ${ }^{6}$ Penelitian lainnya juga mendapati hasil serupa dimana hampir setengah dari responden dalam penelitian tersebut tidak memperoleh penanganan medis yang baik pasca cedera. ${ }^{5}$ Banyak pasien yang lebih memilih untuk tidak menerima perawatan yang diawasi atau dikelola oleh tenaga medis profesional. ${ }^{7}$ Masyarakat masih berpikir bahwa cedera sprain ankle merupakan cedera yang tidak berbahaya dan dapat disembuhkan dengan perawatan yang minimal. Manajemen dini dan perawatan lanjutan dapat memodulasi proses penyembuhan dan mempercepat kembali ke aktivitas yang diinginkan. ${ }^{8}$ Pada penelitian ini sebagian besar responden justru lebih memilih untuk melakukan penanganan secara tradisional. Padahal penanganan yang tidak tepat dapat menjadikan seseorang merasakan gejala sisa dari cedera sebelumnya, cedera berulang hingga berujung mengalami CAI. ${ }^{9}$

Penelitian ini memperoleh hasil sebanyak 83 responden $(51,2 \%)$ mengalami kondisi CAI. Hasil tersebut dapat dikategorikan sangat tinggi. Study sebelumnya menyebutkan prevalensi CAI pada olahraga basket, voli dan sepakbola sangat tinggi mencapai $>25 \% .{ }^{10}$ Simon et al juga mendapatkan hasil yang serupa. Sebanyak $53,2 \%$ responden yang merupakan dancer mengalami CAl. ${ }^{11}$ Penelitian lain yang dilakukan oleh Leuman et al menunjukan prevalensi CAI sebesar $57 \%$ pada atlet orienteering. ${ }^{12}$ Namun studi sebelumnya mengenai prevalensi CAl pada basket justru menunjukan hasil yang lebih sedikit yaitu sebesar $29,8 \% .^{5}$

Prevalensi CAI dibagi lagi menjadi dua jenis, yaitu bilateral dan unilateral. Hasil dari penelitian ini menunjukan CAI bilateral $(54,2 \%)$ lebih banyak dialami oleh responden dibandingkan dengan CAI unilateral $(45,8 \%)$. Studi sebelumnya yang dilakukan oleh Docherty et al mendapatkan hasih serupa, dimana CAI bilateral lebih dominan dibandingkan dengan CAI unilateral. ${ }^{13}$ Perubahan sentral dapat terjadi setelah seseorang mengalami cedera sprain ankle. Perubahan tersebut dapat mempengaruhi pola kontrol motorik dan membuat kerusakan pada pergelangan kaki yang tidak mengalami cedera. Jika satu sisi mengalami cedera, maka sisi lainnya juga dapat terpengaruh oleh cedera tersebut. ${ }^{14}$

Penelitian ini meneliti beberapa faktor yang dianggap mempengaruhi terjadinya CAI pada seseorang. Faktorfaktor tersebut adalah jenis kelamin, IMT, riwayat cedera sprain ankle dan ada atau tidaknya perawatan medis pasca cedera sprain ankle. Distribusi CAI berdasarkan jenis kelamin menunjukan bahwa laki-laki lebih banyak mengalami CAI dibandingkan perempuan. Hasil pada penelitian sebelumnya menunjukan bahwa CAl lebih banyak dialami oleh perempuan dibandingkan dengan laki-laki. ${ }^{5}$ Studi lainnya yang melakukan penelitian untuk membandingkan kejadian cedera berdasarkan jenis kelamin juga kebanyakan mendapatkan hasil bahwa perempuan cenderung untuk mengalami cedera dibandingkan laki-laki. Swenson et al menunjukan rasio cedera sprain ankle atlet SMA lebih banyak pada perempuan. ${ }^{15}$ Namun terdapat pula penelitian terbaru yang menunjukan insiden cedera pergelangan kaki pada atlet basket lebih besar pada laki-laki dibandingkan perempuan. ${ }^{16}$ Penelitian kali ini menunjukan jumlah kejadian CAI lebih banyak dijumpai pada laki-laki. Hal ini mungkin disebabkan karena terdapat lebih banyak responden laki-laki yang memiliki riwayat cedera sprain ankle sebelumnya $(n=56$ dari $88 ; 63,3 \%)$ dibandingkan dengan perempuan $(n=30$ dari $74 ; 40,5 \%$ ), sehingga kejadian CAl lebih banyak ditemukan pada laki-laki dibandingkan perempuan.

Berdasarkan faktor IMT diperoleh hasil distribusi CAI pada kategori overweight lebih besar dibandingkan pada kategori normal dan obesitas. Studi sebelumnya yang dilakukan pada remaja menunjukan hasil bahwa remaja dengan IMT overweight dan obesitas memiliki kecenderungan untuk mengalami CAI. ${ }^{17} \mathrm{Timm}$ et al menyebutkan bahwa anak dengan IMT kategori overweight dan obesitas cenderung lebih berisiko untuk masih merasakan gejala sisa akibat cedera pergelangan kaki sebelumnya, dimana gejala sisa yang dimaksud merujuk pada kondisi CAl. ${ }^{18} \mathrm{Hal}$ tersebut dapat terjadi karena terdapat korelasi antara IMT dengan peroneal reaction time (PRT). Semakin besar IMT seseorang juga berpengaruh terhadap peningkatan PRT dan selanjutnya mempengaruhi penurunan proprioseptif pada pergelangan kaki. ${ }^{19}$ Apabila dilihat dari riwayat cedera sprain ankle, pada IMT normal sebanyak $50,8 \%(n=61$ dari 120) responden pernah mengalaminya. Lebih sedikit jika dibandingkan dengan yang terjadi pada kategori overweight dan 
obesitas yakni $57,1 \%$ ( $n=16$ dari 28 ) dan $64,3 \%$ ( $n=9$ dari 14$)$. Sehingga pada kedua kategori tersebut prevalensi CAI memang seharusnya lebih besar. Tetapi jumlah responden di tiap kategori IMT tidak proporsional. Gambaran yang lebih baik mungkin akan diperoleh apabila jumlah masing-masing kategori tersebut sudah proporsional.

Berdasarkan riwayat cedera sprain ankle diperoleh prevalensi CAI lebih besar pada mereka yang memiliki riwayat cedera dibandingkan yang tidak memiliki. Riwayat cedera sprain ankle saat ini dianggap sebagai faktor yang paling mempengaruhi seseorang untuk mengalami CAI. ${ }^{20} \mathrm{Hal}$ tersebut dapat terjadi karena adanya mechanical laxity pada ligamen penyangga pergelangan kaki setelah cedera sprain ankle. Akibatnya pergelangan kaki menjadi tidak stabil. ${ }^{21}$ Defisit sensorimotor juga terjadi setelah seseorang mengalami sprain ankle. Dimana defisit tersebut mencakup penurunan proprioseptif, fungsi integrasi dari sensorimotor dan aktifitas otot eferen yang menimbulkan perasaan tidak stabil pada individu yang mengalaminya. ${ }^{22}$ Doherty et al juga menyatakan bahwa terdapat penurunan kontrol postural dinamis dalam waktu 6 bulan setelah individu pertama kali cedera sprain ankle yang diprediksi sebagai awal bagi seseorang untuk mengalami CAI. ${ }^{23}$

Distribusi CAI berdasarkan penanganan medis pasca cedera sprain ankle menunjukan bahwa CAI lebih banyak dialami oleh mereka yang memperoleh penanganan medis pasca cedera. Studi sebelumnya menjelaskan bahwa perawatan medis pasca sprain ankle merupakan salah satu faktor yang mempengaruhi CAI, dimana orang yang tidak mendapatkan perawatan medis pasca cedera cenderung masih merasakan gejala sisa hingga mengalami CAl. ${ }^{24}$ Namun tidak menutup kemungkinan pada mereka yang mendapat perawatan medis masih merasakan gejala dan keterbatasan akibat cedera sebelumnya. Kemler et al melaporkan bahwa pasien yang telah mendapatkan perawatan fungsional dari tenaga medis masih merasakan nyeri dan tenderness, bahkan mengalami cedera kembali setelah beberapa tahun. ${ }^{25}$ van Rijn et al pada tahun 2008 juga menyatakan bahwa sediktinya 3- 34\% pasien dapat kembali mengalami sprain ankle setidaknya satu kali selama periode follow-up. ${ }^{26}$. Hasil dari penelitian kali ini menunjukan responden yang mendapat perawatan medis pasca sprain ankle lebih cenderung untuk mengalami CAI. Diketahui bahwa kelompok tersebut memiliki persentase responden yang memiliki IMT kategori overweight dan obesitas yang lebih besar yaitu $27,8 \%(n=5$ dari 18$)$ dan $11,1 \%(n=2$ dari 18$)$. Sedangkan pada responden yang tidak memperoleh penanganan medis pasca cedera, memiliki persentase yang lebih kecil yaitu $16,2 \%(n=11$ dari 68$)$ dan $10,3 \%(n=7$ dari 68$)$. Kemungkinan hal tersebut yang menyebabkan kejadian CAI cenderung lebih banyak pada responden yang memperoleh penanganan medis. Seperti yang sudah dijelaskan sebelumnya bahwa individu dengan IMT overweight dan obesitas memiliki kecenderungan yang lebih besar untuk mengalami CAI dibandingkan dengan IMT normal. ${ }^{18}$ Namun perlu diingat bahwa jumlah responden yang mendapatkan perawatan medis jauh lebih sedikit dibanding yang tidak memperoleh perawatan medis. Kemungkinan diperlukan jumlah yang proporsional untuk masing-masing kondisi agar mendapatkan gambaran yang lebih baik.

\section{SIMPULAN}

Simpulan yang dapat ditarik berdasarkan hasil dan diskusi yang telah dibahas yaitu prevalensi kejadian CAI pada atlet basket SMA di Kabupaten Badung sangat tinggi. Atlet dengan jenis kelamin laki-laki, IMT overweight, dengan riwayat sprain ankle dan memperoleh penanganan medis pasca mengalami cedera sprain ankle memiliki kecenderungan yang lebih besar mengalami CAI.

\section{DAFTAR PUSTAKA}

1. Borowski LA, Yard EE, Fields SK, Comstock RD. The epidemiology of US high school basketball injuries, 20052007. The American journal of sports medicine. 2008;36(12), 2328-2335.

2. Junaidi. Cedera Olahraga pada Atlet Pelatda PON XVIII DKI Jakarta. Jurnal Fisioterapi. 2013;13(1).

3. Santos MJ, Liu W. Possible factors related to functional ankle instability. journal of orthopaedic \& sports physical therapy. 2008;38(3), 150-157.

4. Attenborough AS, Hiller CE, Smith RM, Stuelcken M, Greene A, Sinclair PJ. Chronic ankle instability in sporting populations. Sports Medicine. 2014;44(11), 1545-1556.

5. Tanen L, Docherty CL, Van Der Pol B, Simon J, Schrader J. Prevalence of chronic ankle instability in high school and division I athletes. Foot \& ankle specialist. 2014;7(1), 37-44.

6. McKay GD, Goldie PA, Payne WR, Oakes BW. Ankle injuries in basketball: injury rate and risk factors. British journal of sports medicine. 2001;35(2), 103-108.

7. Gribble PA, Bleakley CM, Caulfield BM, Docherty CL, Fourchet F, Fong DT, Hertel J, Hiller CE, Kaminski TW, McKeon PO, Refshauge KM, Verhagen EA, Vicenzino BT, Wikstrom EA, Delahunt E. 2016 consensus statement of the International Ankle Consortium: prevalence, impact and long-term consequences of lateral ankle sprains. $\mathrm{Br}$ J Sports Med. 2016;50(24), 1493-1495.

8. Kaminski TW, Hertel J, Amendola N, Docherty CL, Dolan MG, Hopkins JT, Nussbaum E, Poppy W, Richie D. National Athletic Trainers' Association position statement: conservative management and prevention of ankle sprains in athletes. Journal of athletic training. 2013;48(4), 528-545.

9. Hiller CE, Kilbreath SL, Refshauge KM. Chronic ankle instability: evolution of the model. Journal of Athletic Training. $2011 ; 46(2), 133-141$

10. Gribble PA, Bleakley CM, Caulfield BM, Docherty CL, Fourchet F, Fong DT, Hertel J, Hiller CE, Kaminski TW, McKeon PO, Refshauge KM, Verhagen EA, Vicenzino BT, Wikstrom EA, Delahunt E. Evidence review for the 2016 International Ankle Consortium consensus statement on the prevalence, impact and long-term consequences of lateral ankle sprains. Br J Sports Med. 2016;50(24), 1496-1505.

11. Simon J, Hall E, Docherty C. Prevalence of chronic ankle instability and associated symptoms in university dance majors: an exploratory study. Journal of Dance Medicine \& Science 2014;18(4), 178-184. 
12. Leumann A, Zuest $P$, Valderrabano V, Clenin G, Marti B, Hintermann B. Chronic ankle instability in the Swiss orienteering national team. Sport-Orthopädie-Sport-Traumatologie-Sports Orthopaedics and Traumatology. 2010;26(1), 20-28.

13. Docherty CL, Gansneder BM, Arnold BL, Hurwitz SR. Development and reliability of the ankle instability instrument. Journal of athletic training. 2006;41(2), 154.

14. McKeon PO, Ingersoll CD, Kerrigan DC, Saliba E, Bennett BC, Hertel J. Balance training improves function and postural control in those with chronic ankle instability. Medicine \& science in sports \& exercise. 2008;40(10), 18101819.

15. Swenson DM, Collins CL, Fields SK, Comstock RD. Epidemiology of US high school sports-related ligamentous ankle injuries, 2005/06-2010/11. Clinical journal of sport medicine: official journal of the Canadian Academy of Sport Medicine. 2013;23(3), 190.

16. de Soto PC, Guillén JF, León AR, Zurita MJ, Quintanilla IM. Epidemiology of injury in a non professional basketball club during a regular season: a prospective study. Archivos de medicina del deporte: revista de la Federación Española de Medicina del Deporte y de la Confederación Iberoamericana de Medicina del Deporte. 2018;(185), 144-149.

17. Hershkovich O, Tenenbaum S, Gordon B, Bruck N, Thein R, Derazne E, Tzur D, Shamiss A, Afek A. A large-scale study on epidemiology and risk factors for chronic ankle instability in young adults. The Journal of Foot and Ankle Surgery. 2015;54(2), 183-187.

18. Timm NL, Grupp-Phelan J, Ho ML. Chronic ankle morbidity in obese children following an acute ankle injury. Archives of pediatrics \& adolescent medicine. 2005;159(1), 33-36.

19. Rein S, Fabian T, Zwipp H, Mittag-Bonsch M, Weindel S. Influence of age, body mass index and leg dominance on functional ankle stability. Foot \& ankle international. 2010;31(5), 423-432.

20. Guillo S, Bauer T, Lee JW, Takao M, Kong SW, Stone JW, Mangone PG, Molloy A, Perera A, Pearce CJ, Michels F, Tourne Y, Ghorbani A, Calder J. Consensus in chronic ankle instability: aetiology, assessment, surgical indications and place for arthroscopy. Orthopaedics \& traumatology: surgery \& research. 2013;99(8), S411-S419.

21. Hubbard TJ, Kramer LC, Denegar CR, Hertel J. Contributing factors to chronic ankle instability. Foot \& ankle international 2007;28(3), 343-354.

22. Hertel J. Sensorimotor deficits with ankle sprains and chronic ankle instability. Clinics in sports medicine. 2008;27(3), 353-370.

23. Doherty C, Bleakley C, Hertel J, Caulfield B, Ryan J, Delahunt E. Recovery from a first-time lateral ankle sprain and the predictors of chronic ankle instability: a prospective cohort analysis. The American journal of sports medicine. 2016;44(4), 995-1003.

24. Pijnenburg AC, Van Dijk CN, Bossuyt PM, Marti RK. Treatment of ruptures of the lateral ankle ligaments: a metaanalysis. JBJS. 2000;82(6), 761-773.

25. Kemler E, Thijs KM, Badenbroek I, van de Port IG, Hoes AW, Backx FJ. Long-term prognosis of acute lateral ankle ligamentous sprains: high incidence of recurrences and residual symptoms. Family practice. 2016;33(6), 596-600.

26. van Rijn RM, Van Os AG, Bernsen RM, Luijsterburg PA, Koes BW, Bierma-Zeinstra SM. What is the clinical course of acute ankle sprains? A systematic literature review. The American journal of medicine 2008;121(4), 324-331 